Alberto Furtado Rahde, professor de farmacologia da PUC/RS, vice-presidente da

Federação Mundial das Associações de

Centros de Toxicologia. Atualmente é presidente da Sociedade Brasileira de Toxicologia e coordenador da Comissão

Consultiva em Toxicologia do Ministério da Saúde.

\title{
Defensivos agrícolas - efeitos no homem e no ambiente
}

A questão dos defensivos agrícolas e suas repercussões no mundo atual - além das bem-claras implicações de utilização como fator de produção agrícola - se reveste de aspectos polêmicos e que até hoje não apresenta consenso universal. Este consenso que aparentemente deveria ficar restrito à ciência agronômica ou à toxicologia, melhor dito, à ecotoxicologia, hoje em dia atinge praticamente os interesses de toda a comunidade e se apresenta como uma questão ainda sem soluções satisfatórias. Muitas vezes o problema dos defensivos agrícolas é cognominado com justa razão de o "dilema" dos defensivos, na conceituação clássica de que qualquer que seja o caminho do raciocínio, as conclusões serão igualmente difíceis e penosas.

Começando pela própria denominação das substâncias usadas para destruir pragas, já não há acordo na nomenclatura a ser utilizada: assim, pesticidas, praguicidas, agrotóxicos, biocidas e defensivos agrícolas - este último cunhado somente no Brasil pelo Ministério da Agricultura, com uma acepção sujeita a inúmeras críticas - entre outros nomes, que tentam a abrangência do significado sem, contudo, atingir plenamente o objetivo da definição completa. Pessoalmente temos a preferência pelo termo "praguicidas", porém não deixaremos questões semânticas prolongarem e esvaziarem a finalidade deste artigo.

Iniciamos pela própria definição de defensivo agrícola ou praguicida, como está sendo proposta pelo Grupo de Trabalho sobre Princípios de
Regulamentação 1 , do Comitê do Codex Alimentarius sobre Resíduos de Pesticidas, congregando áreas da Organização Mundial de Saúde - OMS e da Organização das Nações Unidas para Alimentação e Agricultura - FAO e referendada igualmente pelo Programa das Nações Unidas para o Meio Ambiente - UNEP2, praguicida significa qualquer substância destinada a prevenir, destruir, atrair, repelir ou controlar qualquer praga, inclusive espécies indesejáveis de plantas ou animais, durante a produção, armazenamento, transporte, distribuição e processamento de alimentos, produtos agrícolas ou rações animais, ou que podem ser administradas a animais para controle de ectoparasitas. O termo também se refere a substâncias usadas como reguladores de crescimento de plantas, desfolhantes, dessecantes, antibrotantes e àquelas que são aplicadas às culturas ou antes ou logo após à colheita, para proteger os produtos, durante o armazenamento ou transporte. Não se incluem nesta definição fertilizantes, nutrientes vegetais ou animais, aditivos alimentares ou de rações e produtos veterinários.

Como se pode ver pela complexidade das áreas envolvidas pela definição, um grande número de substâncias são enquadradas como praguicidas agrícolas. Queremos lembrar, inclusive, que a conotação "agrícola" não é absoluta, pois as mesmas substâncias, além da proteção das culturas, também se destinam vetores animais de doenças como malária, esquistossomose, febre amarela, doença de chagas, etc. Assim, nas campanhas de saúde públi- 
ca, os praguicidas utilizados não diferem daqueles usados em agricultura.

Fica bem claro que praguicida ou defensivo agrícola tem uma qualidade ou propriedade de destruição ou de causar a morte de espécies que ameaçam as culturas agrícolas ou a saúde do homem ou dos animais. Por essa razão são chamados de biocidas ou de agrotóxicos, já que a toxicidade acompanha como característica obrigatória a sua ação.

Temos configurado uma situação totalmente inédita: produtos químicos de ação tóxica são colocados deliberada e intencionalmente no ambiente natural, obedecendo a critérios técnicos, com objetivos bem-definidos de exterminação. Este enfoque já evidencia uma situação especial. As últimas décadas foram testemunhas de um desenvolvimento tecnológico espetacular no terreno das sínteses químicas, com produção em alta escala de substâncias, destinadas a uso agrícola, acompanhando a multiplicação das áreas de plantio em todo o mundo. As enormes extensões de culturas modificaram o aspecto original dos ecossistemas e fatores variados, como desmatamento, falta de rodízio em culturas, desertificação e modelos agrícolas industriais, alteraram e destruíram inimigos naturais das pragas. Números bem-conhecidos apontam a destruição de cerca de um terço da produção agrícola, nos seus vários estágios, por pragas, conduzindo, por vezes, de uma maneira inadequada e suicida, a um uso abusivo e descontrolado de praguicidas.

As pragas de insetos, que destruíam culturas inteiras, levando populações à fome e à morte, fazem parte da história da humanidade. Há registros de destruição de colheitas por gafanhotos, no ano 2.500 a.C., como da utilização de produtos vegetais e cinzas no seu combate. $O$ arsênio foi utilizado no Século XVII, bem como a cal, a nicotina, presente no extrato de tabaco, o enxofre, o ácido cianídrico e o piretro, aplicados como primitivos praguicidas. Os vinhedos franceses foram salvos das pragas, no final do século passado pelo tratamento com a chamada "calda bordalesa", mistura de cal e sais de cobre.

Populações inteiras tiveram modificada a sua evolução histórica devido a pragas agrícolas. É bemconhecido o caso da morte por fome de milhares de pessoas na Irlanda, no século passado, devido a uma praga na batata, ocasionando a migração em massa para a América do Norte. A economia do Ceilão, igualmente, sofreu rude golpe, há cerca de cem anos, com a destruição completa das plantações de café, originando a nova cultura do chá, como substitutivo.

A base científica do controle químico das pragas teve início no Século XX, mas foi após a ll Guerra Mundial que a nova era química se intalou, com a descoberta do DDT e a utilização dos organofosforados, inicialmente sintetizados como armas de guerra. Um programa de pesquisa e de novas sínteses fez surgir nos laboratórios um número espetacular de produtos e uma poderosa indústria se desenvolveu, visando a produção de praguicidas.

Não cabe nos limites deste artigo discutir a validade da utilização de praguicidas químicos - esta tarefa de avaliação do benefício cabe à ciência agronômica, única capaz de moldar diretrizes de uma política científica de culturas, de proteção aos resultados essenciais para a alimentação e abastecimento da população mundial. Tarefa complexa, esta atribuição da ciência agronômica deve levar em conta fatores como treinamento de técnicos, pesquisa e um constante desenvolvimento e adequação de situações geoeconômicas, culturais, ecológicas, etc.

Parece ser indubitável, igualmente, o valor da erradicação de vetores de doenças altamente prejudiciais à saúde das populações. As campanhas de saúde pública apresentam um benefício inestimável ao proteger comunidades inteiras e até países de devastações causadas por parasitos e microorganismos veiculados por insetos, caramujos, etc.

O outro lado da situação a ser avaliada, contudo, é a do risco que a utilização destes agentes químicos provoca nos sistemas naturais, considerados como um todo indissolúvel. A utilização de compostos químicos com finalidades altamente seletivas, como a da destruição das pragas, a necessidade de produzir, manipular, transportar e estocar produtos tóxicos, passou a exigir, em escala cada vez maior, uma preocupação com os riscos que todas estas atividades implicavam. "A real preocupação é o risco ou o perigo associado ao uso de produto químico... devendo ser considerados os efeitos nocivos que dele advém direta ou indiretamente pelas alterações no ambiente, quando usados na quantidade e na maneira proposta."3

Procura-se a segurança, difícil de ser conseguida, em termos absolutos. A manipulação mais elementar de um praguicida, como a de transferir o conteúdo de um recipiente para um aparelho ou a limpeza de um derramamento no chão, podem significar riscos de intoxicação para o operário ou contaminação severa para o solo, águas, ar, etc. ${ }^{4}$ químicos?

Quais os riscos de utilização de praguicidas

Esquematicamente são três os segmentos atingidos pela ação direta ou pelos resíduos destas substâncias. Em primeiro lugar temos os trabalhadores diretamente relacionados à produção, industrialização, armazenamento, transporte, aplicação dos praguicidas, isto é, todos aqueles que ocupacio- 
nalmente se envolvem com os produtos. É uma área altamente especializada de controle e segurança do trabalho e, mais do que nunca, de treinamento e esclarecimento dos indivíduos que, por vezes, manejam substâncias de alto risco, completamente ignorantes das conseqüências danosas a curto e longo prazo. No nosso país a capacitação de aplicadores de defensivos, os cuidados de higiene industrial e a indicação cuidadosa da utilização destes produtos é um desafio que está sendo enfrentado com grandes dificuldades, pelo governo, por entidades privadas e pelas universidades.

A seguir, a população em geral pode ser atingida pela ação deletéria dos compostos químicos, através de acidentes, que comprometem a qualidade da água, do solo, do ar e principalmente veiculada pelos resíduos, que uma inadequada prática agrícola faz chegar pelos alimentos, diretamente e indiscriminadamente contaminados. Esta área, de uma formidável expressão social e sanitária, provoca ações de prevenção de doenças tóxicas agudas ou crônicas, seguindo determinações de organismos regulatórios nacionais e internacionais. Nesta tarefa, órgão do Ministério da Saúde regulamentam os níveis permitidos de resíduos de substâncias químicas que podem ser muitas vezes totalmente negativos, de acordo com uma dinâmica de pesquisa apoiada pela OMS e pela FAO.

Por último, a implicação de risco, não menos importante, se refere ao atingimento das estruturas dos ecossistemas, com modificações irresponsáveis da harmonia do equilíbrio ecológico, através da poluição de que são capazes certas substâncias, que apresentam uma persistência de ação na natureza. A conseqüência desta ação se faz sentir na vida selvagem, na qualidade das águas, na desertificação, na impropriedade das condições de desenvolvimento da vida em determinadas áreas do planeta.

Tomar uma posição imparcial, científica e que atente para as necessidades e defesas da comunidade, de uma maneira global, implica permanentemente avaliar os termos da equação risco/benefício. Se por um lado, os benefícios para a sociedade, da utilização dos praguicidas, medidos por produção a menor custo de alimentos, eliminação de vetores animais causadores de doenças e controle de forma de vida que são nocivas, são plenamente justificados, por outro lado há necessidade de se bem-definir o que é risco, se está introduzindo no ambiente natural substâncias que por definição devem ser tóxicas.

Um grande elenco de medidas de avaliação toxicológica dos produtos estão sempre e dinamicamente sendo aplicadas. Estes testes para aceitação e controle de praguicidas incluem testes de toxicidade aguda e subaguda, toxicidade crônica e subcrônica, mutagênese, carcinogênese, teratogênese, assim como éfeitos sobre animais selvagens, persistência e degradação no ambiente, não esquecendo estudos metabólicos, detecção de resíduos, etc.

Um aspecto que merece ênfase especial refere-se a estudos epidemiológicos, isto é, uma avaliação qualitativa e quantitativa do atingimento de populações, sujeitas a intoxicações agudas ou crônicas. Desde 1980, o Ministério da Saúde, preocupado com o problema do risco tóxico, vem desenvolvendo ações no sentido de informar à população em geral e às profissões ligadas à saúde, através de unidades estaduais (centros de informação toxicológica) vinculadas ao Sistema Nacional de Informações Tóxico-Farmacológicas. Já existem unidades em pleno funcionamento no Rio Grande do Sul, paraná, Mato Grosso do Sul, São Paulo, Rio de Janeiro e Bahia. Até o final de 1983 , novas unidades serão ativadas em Santa Catarina, Pernambuco e no Distrito Federal. São armas importantes como instrumentos de informação continuada, igualmente funcionando como indicadores de verificação da ocorrência de acidentes tóxicos.

Os efeitos nocivos dos defensivos agrícolas podem se acentuar conforme uma utilização inadequada e desnecessária. Não existe o praguicida ideal: todos, de uma maneira ou outra, podem desencadear problemas, como os medicamentos que ao atingir o organismo, visando destruir uma causa de doença, desencadeiam efeitos colaterais. Isto provoca inevitavelmente a procura científica, pela pesquisa, de novas formas de controle e erradicação de pragas e utilização de produtos com segurança, sem contaminação do ambiente.

Muitos praguicidas já foram postos fora de uso e pertencem ao passado. Não se pode aceitar que a visão do uso destas substâncias seja estática. Ela deve ser essencialmente dinâmica e evoluir para a maior segurança para as populações e para o ambiente, com firme decisão de atingir um ideal de saúde e de melhor qualidade de vida.

\section{Referências bibliográficas}

1. WORKING GROUP OR REGULATORY PRINCIPLES. Draft; proposed CCPR glossary. 1983.

2. UNITED NATION ENVIRONMENT PROGRAMME. EnglishRussian glossary of selected terms in preventive toxicology; interim document. Moscow, 1982

3. KLAASEN, C.D. Principales of Toxicology. In: Goodman \& Gilman. The pharmacological basis of therapeutics. Macmillan, 1980.

4. MURPHY, S. D. Pesticides. In: Casarett and doull, toxicology, the basic science of poisons. S. 1., Macmillan, 1980. 
Q15

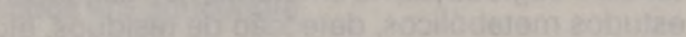

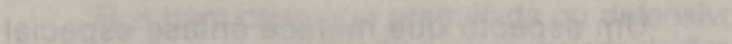

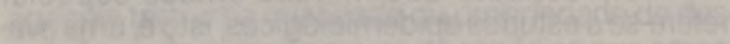

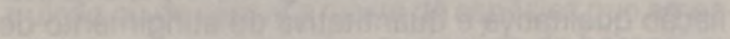

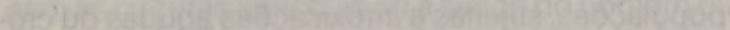

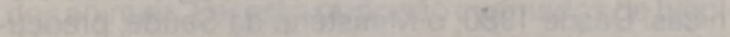

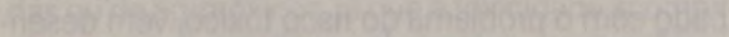

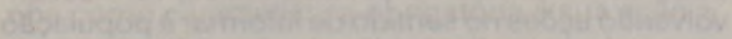

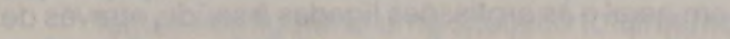

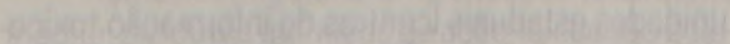

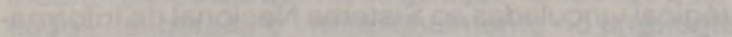

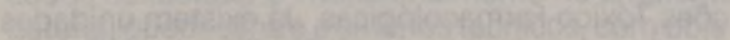

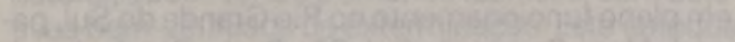

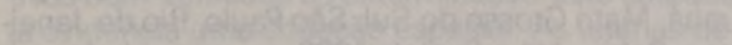

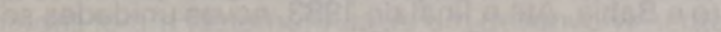

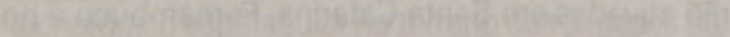

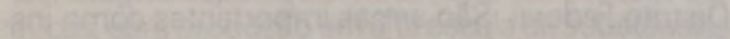

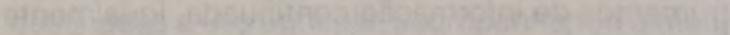

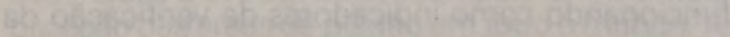

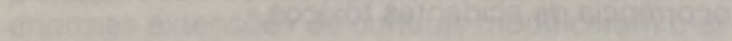

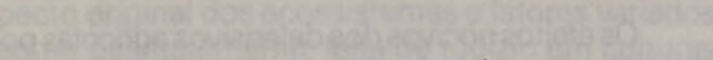

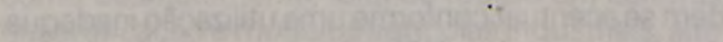

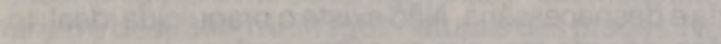

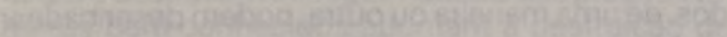

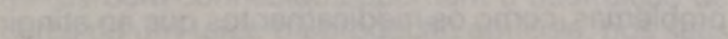

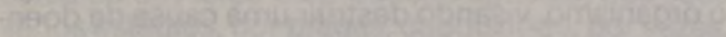

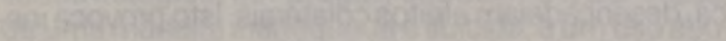

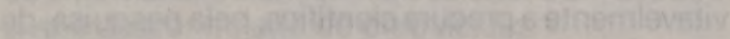

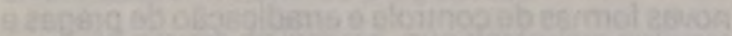

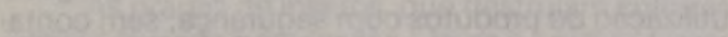

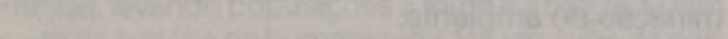

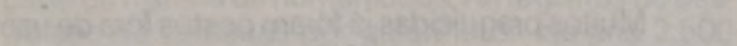

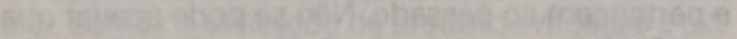

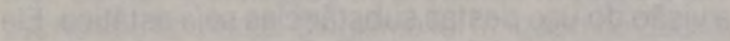

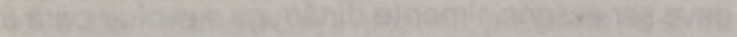

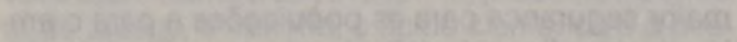

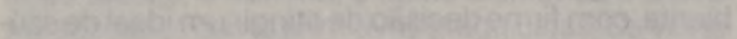

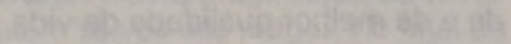

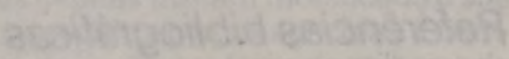

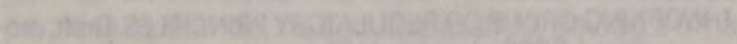

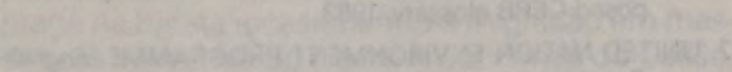

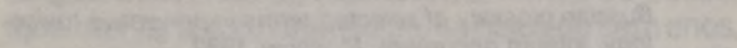

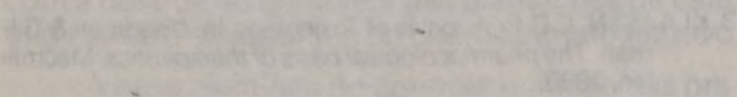

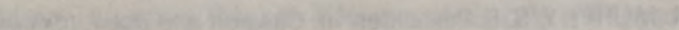

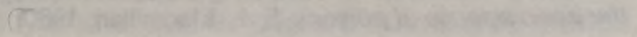

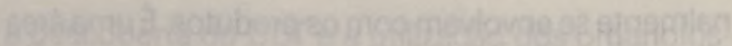

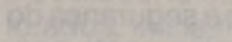

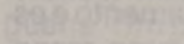

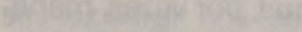

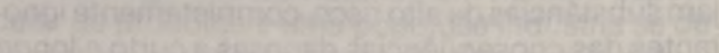

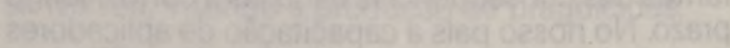

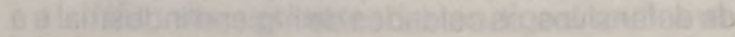

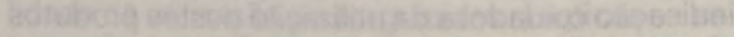

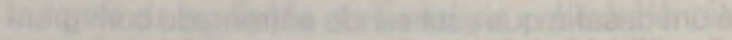

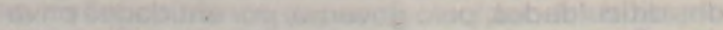

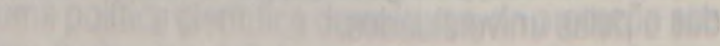

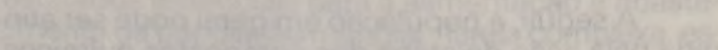

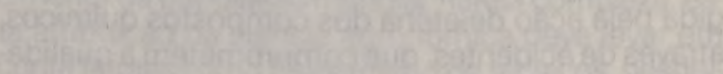

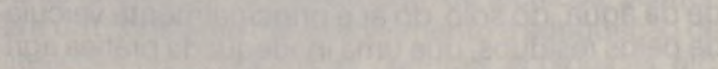

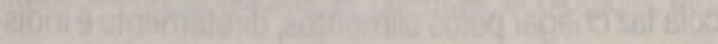

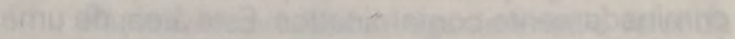

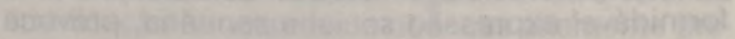

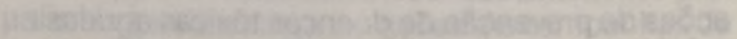

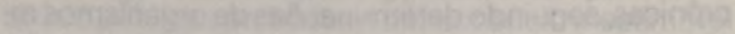

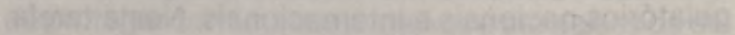

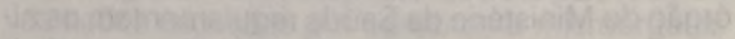

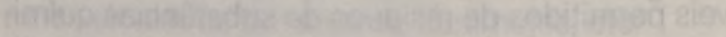

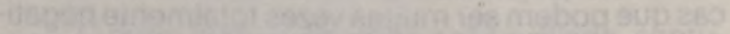

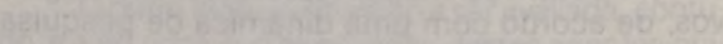

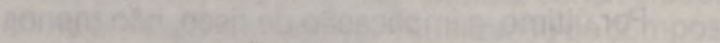

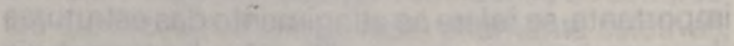

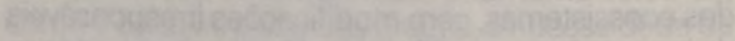

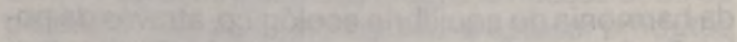

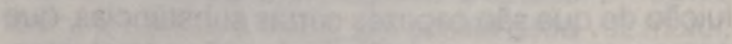

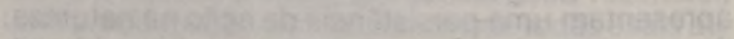

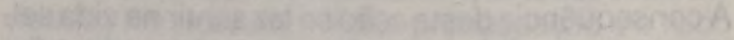

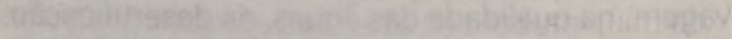

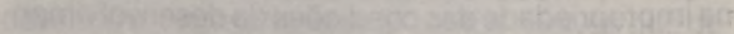

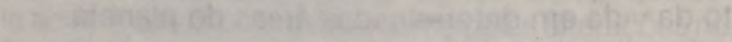

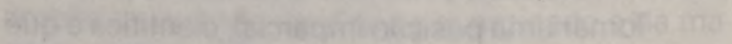

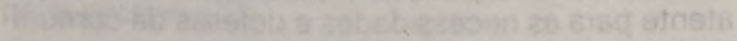

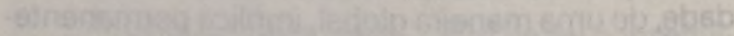

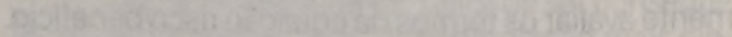

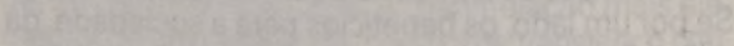

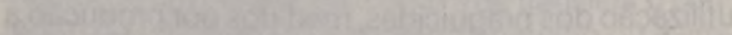

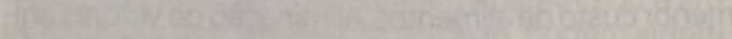

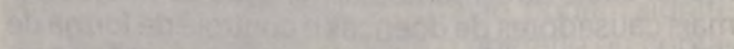

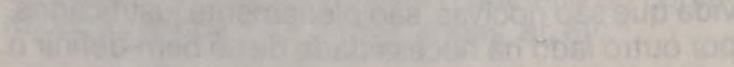

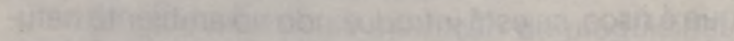

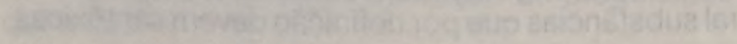

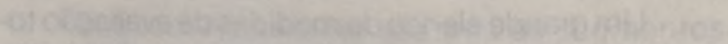

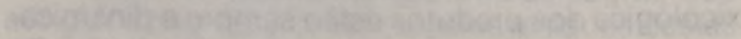

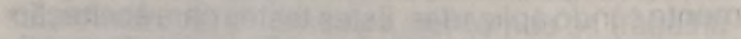

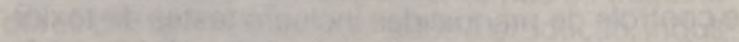

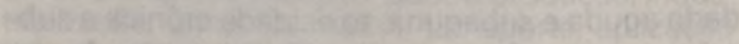

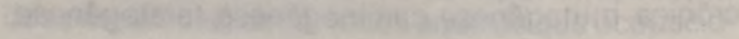

